\title{
Study on Supply Chain Coordination Mechanism of Agricultural Products
}

\author{
Wujun Cao, Maling Zhou, Jinku Zhou \\ Institute of Management Engineering, Zhengzhou University, No. 100 science Avenue, Zhengzhou, China \\ caowujun@zzu.edu.cn,896023218@qq.com,xina1993@163.com
}

Keywords: Supply chain of agricultural products, Revenue sharing contract, Random yield

\begin{abstract}
This paper analyzes coordination in an agricultural supply chain with random yield and random demand. The role of revenue sharing contract in the coordination of supply chain is studied; decentralized decision models of supply chain are built under revenue sharing contract and wholesale price contract. The input decision of the supplier, the ordering decisions of the manufacturer and the profits of all parts in supply chain, are compared under two cases. It is shown that revenue sharing contract can effectively coordinate supply chain under random yield and uncertain demand.

discussed the coordination of the two levels of supply chain, which is composed of single manufacturer and

\section{INTRODUCTION}

China is a big agricultural country. The healthy and sustainable development of agricultural products market is of great significance to the development of China's economy and the improvement of people's living standard. However, the supply chain of agricultural products is composed of different economic entities, and each enterprise has different goals, which often conflict with the overall goal of the system. In order to optimize the supply chain, each member should not only for their own goals, but also consider to other members. Coordinate with other members to achieve the goal of optimizing supply chain.

Due to the influence of many uncertain factors such as weather and season, the output of agricultural single supplier. Qunzhi Wang (2016) puts forward that the flexible supply chain contract based on call option applied to agricultural product supply chain. Yan Liang (2016) studied the coordination of supply chain in the case of uncertainties in the output of raw materials and finished products and the uncertain market demand.

This paper analyzes coordination in an agricultural supply chain with random output and random demand. A centralized optimal decision model, a decentralized decision model and the coordination model of revenue sharing contract are established. Through the analysis of the model, whether the revenue sharing contract can bring the expected profit of supply chain to the level of centralized decision-making, so as to make the supply chain coordinated. Finally, an example is given to verify the correctness of the mathematical model established.
\end{abstract} products is often random. At the same time, producers are also at risk of uncertain demand for finished products. For the above reasons, the supply chain of agricultural products has greater uncertainty risk than other supply chain. Therefore, it is more realistic to study the supply chain of agricultural products with random output and random demand. It is also more helpful for the operation and management of agricultural products.

In recent years, scholars at home and abroad have conducted a great deal of research on supply chain coordination of agricultural products. Güler (2009) studied the coordination of the supply chain with multiple output random suppliers and a single demand random manufacturer and the study showed that only through a single research by revenue sharing contract can not coordinate the supply chain, and proposed that a hybrid contract of revenue sharing, buyback and worst supply penalties could be coordinated. Güler (2013) studied the problem of supply chain coordination between a single supplier and a single retailer under random output and random demand and the study showed that contracts such as revenue sharing and repurchase can coordinate the supply chain. Liuyi Ling (2013) analyzes the influence of agricultural investment, supplier's profit, manufacturer's profit and whole supply chain's profit to take no risk-sharing contract, yield risksharing contract, demand risk-sharing contract and yielddem and risk-sharing contract. Xia Zhao (2014)

\section{PROBLEM DESCRIPTION}

In this paper, we study the agricultural products supply chain with an agricultural supplier and a manufacturer. The goal of all members of the supply chain is to maximize their own interests. Due to the influence of many uncontrollable factors such as weather and season, when the supplier invests a certain amount of agricultural capital, its actual output is uncertain. So, it can be assumed that the input of suppliers is $t$, the actual output is $t Y$. $Y$ is a non-negative random variable, whose distribution function is $G(y)$, the probability density function is $g(y)$. At the same time, the manufacturer sell processed agricultural products in the consumer market, the demand is also uncertain. Therefore, it can be assumed that the market demand of finished products is $X$, whose distribution function is $F(x)$, the probability density function is $f(x)$.

The decision order of this paper is as follows:

1) The manufacturer determines the purchase quantity of raw materials $q$ according to market demand and some parameters;

2) Suppliers according to the manufacturer's orders and other parameters to determine the agricultural capital 
investment $t$, and put into production;

3) After raw material output, if the output volume is greater than the purchase quantity, the supplier shall dispose of the excess parts. If the output volume is less than the volume of the order, the supplier will purchase the insufficient part from the spot market to meet the manufacturer's demand;

4) After the manufacturer obtains the raw materials, the manufacturer shall manufacture and sell the raw materials.

The notation we use is as follows:

$p$-- The retail price of finished products, exogenous variables;

$q$-- Manufacturer's raw material order quantity ,the manufacturer's decision variables;

$c_{m}$-- The cost of producing finished products by the manufacturer;

$c_{S}$-- The production cost of supplier unit;

$W$-- The supplier sells the wholesale price of each raw material;

$S$-- The supplier deals with the benefits of excess raw materials, $S<c_{S}$;

$u$-- The cost of purchasing raw materials from the market, $c_{s}<u$;

$t$-- The supplier inputs, decision variables;

$X$-- Market demand for finished products, a nonnegative random variable, whose distribution function is $F(x)$, the probability density function is $f(x)$.

$Y$-- Output random factor, a non-negative random variable, whose distribution function is $G(y)$, the probability density function is $g(y), E(y)=\mu$;

$z$-- The ratio of raw material output to input, $z=q / t$

$\varphi$-- Income sharing coefficient. That is, after the sales season ,the manufacturer retains the proportion of its earnings;

$\Pi_{S} 、 \Pi_{m} 、 \Pi_{L}$ profit of suppliers, manufacturers and supply chain;

$\prod_{L}^{c}$ Supply chain profit when centralized decision making, $\Pi_{i}^{*}$ The optimal profit of each member of the supply chain when uncoordinated, $\prod_{i}^{z}$ The optimal profit of the members of the supply chain under the revenue sharing contract.

To facilitate the discussion, make the following assumptions:

1) Only consider the coordination of suppliers and manufacturers in a sales period;

2) In this supply chain, the supplier and manufacturer information symmetry;

3) Supply chain members are rational and riskneutral;

4) In order to simplify the calculation without affecting the conclusion, the manufacturer's residual value and the shortage cost are not considered;

5) The sales price of finished products is greater than the purchase cost of raw materials plus the production cost, that is $p>W+c_{m}$;
6) The wholesale price of raw materials for suppliers is greater than the production cost, that is $W>C_{S}$;

7) The residual value of the supplier's surplus products is lower than the production cost, that is $S<c_{S}$, ensuring that the supplier cannot obtain profits through excessive production;

8) Supplier buy raw material cost from the market is higher than the cost of production, that is $c_{S}<u$, ensuring that supplier will organize production, but not all buy products from the market to meet the needs of manufacturers;

9)The cost of purchasing raw materials from the spot market is higher than its wholesale price, that is $u>W$, ensuring that the manufacturer buys raw material from the supplier rather than directly from the market.

\section{THE MODEL AND THE CENTRALIZED SETTING}

In this section we analyze the centralized supply chain consisting of a supplier and a manufacturer. The members of the supply chain belong to the same stakeholder, and the goal is to maximize the profitability of the entire supply chain. The profitability of the entire supply chain under centralized decision is as follows:

$$
\begin{array}{r}
\prod_{L}^{c}=p \min (q, X)-u[q-Y t]^{+} \\
+s[Y t-q]^{+}-c_{m} q-c_{s} t(1) \\
\mathrm{E}\left(\prod_{L}^{c}\right)=p \int_{0}^{q} x f(x) d x+(u-s) t \int_{0}^{q / t} y g(y) d y \\
-p q F(q)+\mu s t+(s-u) q G\left(\frac{q}{t}\right) \\
+\left(p-s-c_{m}\right) q-c_{S} t(2)
\end{array}
$$

The items in the formula (1) are the income from the sale of the final product by the manufacturer, the purchase cost of the raw material purchased from the spot market, the residual value of the raw material sold by the supplier, the manufacturer's production cost, and the production cost of the supplier.

Theorem 1. Under the centralized decision making, the expectation profit of the whole supply chain is maximized to satisfy the following conditions:

$$
F\left(q^{c}\right)=\frac{p-s-c_{m}-(u-s) G\left(\frac{q^{c}}{t^{c}}\right)}{p}
$$

$t^{c}$ and $q^{c}$ are the optimal input of the supplier and the optimal order quantity of the retailer under the centralized decision.

Proof: First, in the formula (2), a first-order partial derivative of $q$ and $t$, the results are as follows: 


$$
\begin{gathered}
\frac{\partial \mathrm{E}\left(\prod_{L}^{c}\right)}{\partial q}=(s-u) G\left(\frac{q}{t}\right)+p-s-c_{m}-p F(q) \\
\frac{\partial \mathrm{E}\left(\prod_{L}^{c}\right)}{\partial t}=(u-s) \int_{0}^{q / t} y g(y) d y+\mu s-c_{S}
\end{gathered}
$$

Then, in the formula (5), a first-order partial derivative of $q$ and in the formula (6) , a first-order partial derivative of $t$, the results are as follows:

$$
\begin{gathered}
\frac{\partial^{2} \mathrm{E}\left(\prod_{L}^{c}\right)}{\partial q^{2}}=\frac{s-u}{t} g\left(\frac{q}{t}\right)-p f(q) \\
\frac{\partial^{2} \mathrm{E}\left(\prod_{L}^{c}\right)}{\partial t^{2}}=-\frac{q^{2}}{t^{3}}(u-s) g\left(\frac{q}{t}\right)
\end{gathered}
$$

Finally, in the formula (5), a first-order partial derivative of $t$ and in the formula (6) , a first-order partial derivative of $q$, the results are as follows:

$$
\frac{\partial^{2} \mathrm{E}\left(\prod_{L}^{c}\right)}{\partial q \partial t}=\frac{\partial^{2} \mathrm{E}\left(\prod_{L}^{c}\right)}{\partial t \partial q}=\frac{q}{\mathrm{t}^{2}}(u-s) g\left(\frac{q}{t}\right)
$$

Then, can get the Hessian Matrix , as follows:

$$
H(q, t)=\left[\begin{array}{ll}
\frac{\partial^{2} \mathrm{E}\left(\prod_{L}^{c}\right)}{\partial q^{2}} & \frac{\partial^{2} \mathrm{E}\left(\prod_{L}^{c}\right)}{\partial q \partial t} \\
\frac{\partial^{2} \mathrm{E}\left(\prod_{L}^{c}\right)}{\partial t \partial q} & \frac{\partial^{2} \mathrm{E}\left(\prod_{L}^{c}\right)}{\partial t^{2}}
\end{array}\right]
$$

Find the Hessian Matrix is negative, so we can see that there is a unique set of $\left(t^{c}, q^{c}\right)$, so that $\mathrm{E}\left(\prod_{L}^{c}\right)$ obtains the maximum value.

When $\frac{\partial \mathrm{E}\left(\prod_{L}^{c}\right)}{\partial q}=0$ and $\frac{\partial \mathrm{E}\left(\Pi_{L}^{c}\right)}{\partial t}=0$, the supply chain can get the best profit.

Bring (3) and (4) into (2), we can find the profit of the whole supply chain under centralized decision, as follows:

$$
\mathrm{E}\left(\Pi_{L}^{c}\right)=p \int_{0}^{q^{c}} x f(x) d x
$$

Since $z^{c}=\frac{q^{c}}{t^{c}}$, we can see that $Z^{c}$ is determined by the unit cost of the supplier, the cost of purchasing raw materials from the spot market, the residual value of the unit and the distribution factor of the output factor. Under the given contract parameters, the specific value of $Z^{c}$ can be obtained, and under the centralized decision, the ratio of the optimal input amount of the supplier and the optimal order quantity of the retailer will remain unchanged.

\section{INDEPENDENT UNCOORDINATED MODEL}

When the members of the supply chain do not belong to the same stakeholder, they will make independent decisions and try to maximize their own interests. In the absence of effective contract to coordinate the supply chain, the supply chain members to maximize their own profits at the same time is often difficult to make the entire supply chain profits the most. Under the wholesale price contract, the manufacturer determines the order quantity based on the wholesale price and demand distribution function to maximize its own benefits. In this paper, we analyze the decentralized decision-making situation based on the wholesale price contract, the optimal decision of the manufacturer and the supplier.

\subsection{Manufacturer's Decision-making Model}

Under independent without coordination, the profit of the manufacturer is as follows:

$$
\begin{array}{r}
\prod_{m}=p \min (q, X)-w q-c_{m} q(7) \\
\mathrm{E}\left(\prod_{m}\right)=p \int_{0}^{q} x f(x) d x-p q F(q)+\left(p-w-c_{m}\right) q
\end{array}
$$

The items in the formula (7) are the proceeds from the sale of the final product, the cost of the purchase of raw materials and the cost of production by the manufacturer.

Theorem 2. There is a unique optimal decision variable $q^{*}$, which makes the manufacturer's expected profit reach the maximum value, and $q^{*}$ satisfies:

$$
q^{*}=F^{-1}\left(\frac{p-W-c_{m}}{p}\right)
$$

Proof: First by the manufacturer's profit function knows $\frac{d^{2} \mathrm{E}\left(\prod_{m}\right)}{d q^{2}}=-p f(q)<0$, that is, the manufacturer has the greatest profit. And then, by the first order is equal to zero, the manufacturer can get the optimal order for the $q^{*}$.

Bring (9) into (8), under independent without coordination the manufacturer's best profit is as follows:

$$
\mathrm{E}\left(\prod_{m}^{*}\right)=p \int_{0}^{q^{*}} x f(x) d x
$$

From the theorem 2, we can know that in the supply chain without independent operation, the manufacturer makes the decision based on the retail price, the wholesale price, the production cost and the demand uncertainty, and the optimal order quantity exists only.

\subsection{Supplier's Decision-making Model}

Under independent without coordination, the profit of the supplier is as follows:

$$
\begin{array}{r}
\prod_{s}=w q-u[q-Y t]^{+}+s[Y t-q]^{+}-c_{s} t(10) \\
\mathrm{E}\left(\prod_{s}\right)=(u-s) t \int_{0}^{q / t} y g(y) d y+(s-u) q G\left(\frac{q}{t}\right) \\
+\mu s t+(w-s) q-c_{s} t(11)
\end{array}
$$

The items in the formula (10) are the sales proceeds of the suppliers, the purchase costs required to purchase the parts from the spot market, the residual value gains and the production costs of the unsold products.

Theorem 3. There is a unique optimal decision variable $t^{*}$, which makes the supplier's expected profit 
reach the maximum value, and $t^{*}$ satisfies:

$$
\int_{0}^{q^{*} / t^{*}} y g(y) d y=\frac{c_{S}-\mu S}{u-S}
$$

Proof of Theorem 3 is the same as Theorem 2.

Bring (12) into (11), under independent without coordination the supplier 's best profit is as follows:

$$
\begin{aligned}
& \mathrm{E}\left(\prod_{S}^{*}\right)=\left[W-s-(u-s) G\left(z^{*}\right)\right\rfloor q^{*} \\
= & {\left[W-s-(u-s) G\left(z^{*}\right)\right] F^{-1}\left(\frac{p-W-c_{m}}{p}\right) }
\end{aligned}
$$

It can be seen from the proposition 3 that in the independent and uncoordinated supply chain, the supplier makes the decision based on the manufacturer's order quantity, the production cost, the cost of purchasing the raw material from the market, the residual value of the surplus product and the production uncertainty , and the optimal input only exists.

\section{USING REVENUE SHARING TO ACHIEVE SUPPLY CHAIN COORDINATION}

Revenue sharing contract refers to a kind of contractual way that the supply chain members make reasonable distribution of the sales income of the final product and share the market risk under the condition of lower wholesale price, so as to improve the efficiency of the supply chain.

This paper sets the revenue sharing contract between the supplier and the manufacturer, so that the expected profit of the supply chain reaches the level of centralized decision-making. Under the revenue sharing contract, the supplier sells the product to the manufacturer at a lower price, but as compensation, the supplier has to share part of the manufacturer's earnings in proportion to $1-\varphi$, then the producer's profit ratio is $\varphi$. The supplier and the manufacturer negotiate the common contract parameters $(\mathrm{w}, \varphi)$.

\subsection{Manufacturer's Decision Model under the Revenue Sharing Contract}

Under the revenue sharing contract, the manufacturer's profit is as follows:

$$
\begin{array}{r}
\prod_{m}=\varphi p \min (q, X)-w q-c_{m} q(13) \\
\mathrm{E}\left(\prod_{m}\right)=\varphi p \int_{0}^{q} x f(x) d x-\varphi p q F(q) \\
+\varphi p q-w q-c_{m} q(14)
\end{array}
$$

The items in the formula (13) are the portion of the proceeds retained under the revenue sharing contract, the cost of purchasing raw materials and the cost of production.

Theorem 4. Under the revenue sharing contract, there is a unique optimal decision variable $q^{z}$, which makes the manufacturer's expected profit maximum and $q^{Z}$ satisfies:

$$
q^{z}=F^{-1}\left(\frac{\varphi p-W-c_{m}}{\varphi p}\right)
$$

Proof of Theorem 4 is the same as Theorem 2.

\subsection{Supplier's Decision Model under the Revenue Sharing Contract}

Under the revenue sharing contract, the profit of the supplier is as follows:

$$
\begin{array}{r}
\prod_{s}=(1-\varphi) p \min (q, X)+w q-u[q-Y t]^{+} \\
+s[Y t-q]^{+}-c_{s} t(16) \\
\mathrm{E}\left(\prod_{s}\right)=(1-\varphi) p \int_{0}^{q} x f(x) d x+(1-\varphi) p q \\
-(1-\varphi) p q F(q)+(s-u) q G\left(\frac{q}{t}\right) \\
+(u-s) t \int_{0}^{q / t} y g(y) d y+\mu s t+(w-s) q-c_{S} t
\end{array}
$$

The items in the formula (16) are the benefits of the manufacturer, the sales proceeds of the supplier, the purchase cost of the purchased product from the spot market, the residual value of the unsold product, and the production cost.

Theorem 5. Under the revenue sharing contract, there is a unique optimal decision variable $t^{z}$, which makes the supplier's expected profit the maximum and $t^{Z}$ satisfies:

$$
\int_{0}^{q^{z} / t^{z}} y g(y) d y=\frac{c_{s}-\mu s}{u-S}
$$

Proof of Theorem 5 is the same as Theorem 2 .

According to (4), (12) and (18), we can get $Z^{\mathrm{z}}=z^{*}=Z^{c}$, that is, the ratio of the optimal order quantity of the manufacturer to the optimal investment amount of the supplier is always the same.

Theorem 6. Under the revenue sharing contract, when the wholesale price $w$ satisfies (19), the supply chain can be coordinated.

$$
W=\left\lfloor s+c_{m}+(u-s) G\left(z^{c}\right)\right\rfloor \varphi-c_{m}
$$

Proof: In order to make the order of the manufacturer's decision-making during decentralized order is the same as the amount ordered during centralized decision making, that is, $q^{Z}=q^{c}$. According to (3) and (15), can get the wholesale price, that is, the establishment of the equation can make the supply chain coordination.

Bring (15)、 (18)and(19)into (14) and (17), you can get the expected profit of the manufacturer and supplier under the revenue sharing contract respectively.

$$
\begin{gathered}
\mathrm{E}\left(\prod_{m}^{z}\right)=\varphi p \int_{0}^{q^{z}} x f(x) d x=\varphi \mathrm{E}\left(\prod_{T}^{c}\right) \\
\mathrm{E}\left(\prod_{S}^{z}\right)=(1-\varphi) p \int_{0}^{q^{z}} x f(x) d x
\end{gathered}
$$




$$
=(1-\varphi) \mathrm{E}\left(\prod_{T}^{c}\right)
$$

Theorem 7. In the case of a revenue sharing contract, when $\varphi$ satisfies (18), it is possible to ensure that both the supplier and the manufacturer can accept the contract.

$$
\frac{\mathrm{E}\left(\prod_{m}^{*}\right)}{\mathrm{E}\left(\prod_{T}^{c}\right)} \leq \varphi \leq 1-\frac{\mathrm{E}\left(\prod_{S}^{*}\right)}{\mathrm{E}\left(\prod_{T}^{c}\right)}
$$

Prove: In order to ensure that the two sides can accept the contract, we must ensure that the expected profit under the income sharing contract is not less than the expected return on the independent decision-making, that is, the following two inequalities:

$$
\begin{aligned}
& \mathrm{E}\left(\prod_{m}^{z}\right) \geq \mathrm{E}\left(\prod_{m}^{*}\right) \\
& \mathrm{E}\left(\prod_{S}^{z}\right) \geq \mathrm{E}\left(\prod_{S}^{*}\right)
\end{aligned}
$$

That is

$$
\begin{gathered}
\varphi \mathrm{E}\left(\prod_{T}^{c}\right) \geq \mathrm{E}\left(\prod_{m}^{*}\right) \\
(1-\varphi) \mathrm{E}\left(\prod_{T}^{c}\right) \geq \mathrm{E}\left(\prod_{S}^{*}\right) \\
\frac{\mathrm{E}\left(\prod_{m}^{*}\right)}{\mathrm{E}\left(\prod_{T}^{c}\right)} \leq \varphi \leq 1-\frac{\mathrm{E}\left(\prod_{s}^{*}\right)}{\mathrm{E}\left(\prod_{T}^{c}\right)}
\end{gathered}
$$

\begin{tabular}{|c|c|c|c|c|c|c|c|}
\hline \multirow[t]{2}{*}{ model } & \multirow{2}{*}{$\begin{array}{c}\begin{array}{c}\text { Income } \\
\text { sharing } \\
\text { coefficient }\end{array} \\
\varphi\end{array}$} & \multirow{2}{*}{$\begin{array}{c}\begin{array}{c}\text { Wholesale } \\
\text { price }\end{array} \\
\mathrm{W}\end{array}$} & \multirow{2}{*}{$\begin{array}{c}\begin{array}{c}\text { optimal } \\
\text { inputs } \\
\text { quantity }\end{array} \\
\mathrm{t}\end{array}$} & \multirow{2}{*}{$\begin{array}{c}\begin{array}{c}\text { Optimal } \\
\text { order } \\
\text { quantity }\end{array} \\
\mathrm{q}\end{array}$} & \multicolumn{3}{|c|}{ Best expected profit } \\
\hline & & & & & $\mathrm{E}\left(\prod_{s}\right)$ & $\mathrm{E}\left(\prod_{m}\right)$ & $\mathrm{E}\left(\prod_{L}\right)$ \\
\hline $\begin{array}{l}\text { Centralized } \\
\text { decision model } \\
\text { Independent }\end{array}$ & & & 69 & 89 & & & 135.66 \\
\hline $\begin{array}{c}\text { uncoordinated } \\
\text { model }\end{array}$ & & 4 & 58 & 75 & 51.84 & 72.73 & 124.57 \\
\hline \multirow{8}{*}{$\begin{array}{l}\text { Revenue sharing } \\
\text { contract } \\
\text { coordination } \\
\text { model }\end{array}$} & 0.39 & 0.46 & 69 & 89 & 52.91 & 82.75 & 135.66 \\
\hline & 0.40 & 0.5 & 69 & 89 & 54.27 & 81.39 & 135.66 \\
\hline & 0.41 & 0.54 & 69 & 89 & 55.62 & 80.04 & 135.66 \\
\hline & 0.42 & 0.57 & 69 & 89 & 56.98 & 78.68 & 135.66 \\
\hline & 0.43 & 0.61 & 69 & 89 & 58.33 & 77.33 & 135.66 \\
\hline & 0.44 & 0.65 & 69 & 89 & 59.69 & 75.97 & 135.66 \\
\hline & 0.45 & 0.69 & 69 & 89 & 61.05 & 74.61 & 135.66 \\
\hline & 0.46 & 0.72 & 69 & 89 & 62.40 & 73.26 & 135.66 \\
\hline
\end{tabular}

Determining the benefit sharing factor in the feasible range of formula (20) ensures that both parties are able

Table 1: The profits of manufacturers and suppliers under different circumstances

As can be seen from Table 1, under the revenue sharing contract:

1)The optimal order quantity of the manufacturer is equal to the order quantity under centralized decision making, which is greater than the order quantity when there is no coordination.

2) The optimal input of the supplier is equal to the amount of agricultural inputs under centralized decision making, which is greater than the amount of agricultural inputs when there is no coordination.

3) The expected profit of the manufacturer and the supplier is greater than the expected profit when there is no coordination.

4) The total profit of the supply chain is equal to the to accept the contract. But what value is given to the supply chain and the ability to negotiate with each other. The greater the bargaining power of the manufacturer, the greater the revenue sharing coefficient, the stronger the bargaining power of the supplier, the smaller the revenue sharing coefficient.

\section{EXAMPLES}

In this section, we use an example to verify the synergistic effect of the revenue sharing contract on this supply chain. It is assumed that the relevant parameters of a supply chain of agricultural products are as follows:

$$
\begin{gathered}
p=6, c_{m}=1, c_{S}=2, s=1, u=5, W=4, \\
Y \sim U(0.6,1), X \sim U(50,100), E(Y)=\mu=0.8
\end{gathered}
$$

By calculation, when $0.39 \leq \varphi \leq 0.46$, the supplier and the manufacturer will accept the revenue sharing contract. Through calculation, the expected profits of suppliers and manufacturers under centralized decision making, decentralized non-coordination and benefit sharing coordination, as shown in Table 1. revenue sharing factor depends on their position in the profits of the centralized decision-making. Within the scope of the available benefit sharing factor, the expected profit of the manufacturer and the supplier is always greater than the expected return when there is no coordination.

\section{CONCLUSIONS}

This paper studies the coordination problem of the two-level supply chain under the uncertain raw material output and uncertain market demand. In this paper, the centralized decision-making model of supply chain, decentralized uncoordinated decision model and revenue 
sharing contract coordination model are established. The research shows that under the uncertainty of output and demand, in the decentralized and uncoordinated supply chain, the optimal input quantity of the supplier and the manufacturer's optimal order quantity exist only; Revenue sharing coordination contract can reduce the impact of supplier output and manufacturer's uncertainty on supply chain benefits and achieve perfect coordination of supply chain.

This paper shows that through the benefit sharing coordination mechanism, the impact of output and demand uncertainty on the supply chain can be reduced, so that the revenue of the supply chain can achieve the benefit of the supply chain in the centralized decisionmaking under the coordination of the revenue sharing contract. This has the important practical significance for the agricultural product supply chain with output and demand uncertainty to overcome the adverse effects of output and demand uncertainty, to carry out scientific operation and coordination decision, so as to maximize the profit of the supply chain as a whole.

\section{REFERENCES}

[1] Chen, F. Y., Yano, C. A., 2010. Improving supply chain performance and managing risk under weather-related demand uncertainty. Management Science, 56(8), pp.1380-1397.

[2] Güler, M. G., Bilgiç, T., 2009. On coordinating an assembly system under random yield and random demand. European Journal of Operational Research, 196(1), pp.342-350.

[3] Güler, M. G., Keski N, M. E., 2013. On coordination under random yield and random demand. Expert Systems with Applications, 40(9), pp.3688-3695.

[4] He, Y., Zhang, J., 2010. Random yield supply chain with a yield dependent secondary market. European Journal of Operational Research, 206(1), pp.221-230.

[5] Liuyi Ling, Xiaolong Guo, Zhongju Hu, Liang Liang, 2013. The risk-sharing contracts under random yield and stochastic demand in agricultural supply chain. Chinese Journal of Management Science, 21(2), pp.50-57.

[6] Qunzhi Wang, Qin Xiang, Huan Wang, 2016. Research on option-based supply contract in agricultural product supply chain. Journal of Transportation Engineering and Information, 14(4), pp.1-9.

[7] Xia Zhao, Fangwei Wu, Rong Cai, 2014. Research on coordination of two-stage supply chain under random yield and random demand with contracts. Journal of Management Sciences in China, 17(8), pp.34-47.

[8] Yan Liang, 2016. Research on revenue sharing contract mechanism in supply chain with uncertainties in two-level yield and demand. Mathematics in Practice and Theory, 46(12), pp.1-10. 